\title{
La política exterior de Chile y su ideología desde 1990*
}

\author{
Foreign Policy in Chile and their Ideology since 1990
}

\author{
Sergio González Pizarro ${ }^{\text {a }}$ \\ Universidad Arturo Prat, Chile \\ sergiogpizarro@gmail.com \\ ORCID: http://orcid.org/0000-0001-5514-5184
}

\author{
DOI: https://doi.org/10.11144/Javeriana.papo24-1.peci \\ Redalyc: http://www.redalyc.org/articulo.oa $? \mathrm{id}=77760192006$ \\ Fecha de recepción: 22 Agosto 2018 \\ Fecha de aprobación: 02 Diciembre 2018 \\ Fecha de publicación: 24 Junio 2019
}

\section{Resumen:}

El objetivo del presente trabajo es en analizar la política exterior de Chile desde 1990, enfocándose particularmente en sus aspectos ideacionales, discursivos y materiales. Mediante el lente de la Teoría Crítica en las Relaciones Internacionales, se tiene en consideración una amalgama de ideas, discursos, estrategias y acciones que encierran la ideología orgánica de la política exterior de Chile desde 1990. Este artículo ofrece un recorrido cronológico y un breve análisis sobre la ideología orgánica de esta política exterior, que se caracteriza por una autopercepción de superioridad nacional, el valor por el territorio y la ley, como también el aislacionismo regional y su apertura comercial monoproductiva con las grandes potencias, entre otras características. En definitiva, Chile en un estilo pragmático y camaleónico, se ha moldeado a un contexto hegemónico transnacional, en virtud de los intereses ideológicos, económicos y políticos de dominación de elites.

Palabras clave: política exterior, ideología, teoría crítica, relaciones internacionales, Chile.

\section{Abstract:}

This work aims to analyze the foreign policy in Chile since 1990 with a particular focus on the ideational, discursive and material aspects. Through the lens of the Critical Theory on the international relations, the blending of ideas, discourses, strategies and actions embracing organic ideology of the Chilean foreign policy since 1990 is considered herein. This article provides a chronological tour and a brief analysis of the organic ideology underlying the said foreign policy, which characterizes by a selfperception of national superiority, the valuation of the territory and the law, and also the regional isolationism and monoproduct commercial opening to the big powers, among other characteristics. In conclusion, Chile with a pragmatic and chameleon-like style has shaped a transitional hegemonic context, by virtue of ideological, economic and political interests of the dominant elites.

Keywords: foreign policy, ideology, critical theory, international relations, Chile.

\section{Introducción}

La política exterior de Chile, desde el regreso a la democracia, ha mantenido una dinámica estable, sostenida en el pragmatismo respecto a la inserción internacional de la nación en el sistema internacional, lo que ha unido a la élite nacional en un sentido común. Esto es reflejo de un consenso que entiende la política exterior como una política de Estado que permite reunir a los dos principales conglomerados que han gobernado desde el término de la dictadura militar ${ }^{[1]}$ en un territorio común: objetivo estratégico de la Concertación de Partidos por la Democracia, plasmado ya desde su Programa de Gobierno de 1989, para la reinserción internacional de Chile (Portales, 2011; Witker, 2000).

El contexto internacional, en el periodo de la restauración de la democracia en Chile, era el de posguerra fría, un mundo en globalización, lo que influyó, en parte, en que este país apostara en materia de política exterior a la estrategia unilateral de rebajas de aranceles, como primera instancia, manteniendo lo establecido en la época dictatorial previa (Fuentes, 2014), para luego dar paso a métodos bilaterales, por medio de

Notas de autor:

a Autor de correspondencia. Correo electrónico: sergiogpizarro@gmail.com 
Tratados de Libre Comercio, y multilaterales, a través de la reinserción y participación en organismos globales y regionales. Por consiguiente, Chile logra nuevamente insertarse en el sistema internacional, desapegándose del aislamiento político internacional, y accionando un rol comprometido, principalmente con el vínculo económico, por medio de tratados comerciales e internacionales con las grandes potencias o potencias emergentes, implementando la estrategia del regionalismo abierto (Aranda y Riquelme, 2011; Bernal-Meza, 2016; Fermandois, 2006; Van Klaveren, 1997, 2011).

Aquella política exterior ${ }^{[2]}$ ha sido pensada, materializada e institucionalizada en la práctica por gobernantes que concretizan a través de estas acciones, una ideología orgánica influenciada, o en palabras de Cox (1981), presionada y limitada por la estructura o el bloque históricos dominantes de la época, lo que se refleja no solo en las fuerzas sociales de esta política exterior, sino también en el proyecto de Estado-nación y sociedad civil, desde la vuelta a la democracia.

Esta política exterior, y su correspondiente ideología, que en su constitución contiene ideas, prácticas y discursos, es la que se presenta como un desafío al ser analizada. El objetivo de esta investigación es comprender, mediante una óptica crítica y analítica, los elementos de la política exterior de Chile desde 1990 a la actualidad, problematizando a la vez, la política doméstica de este Estado-nación, concibiendo tanto la política interna como la externa, como dimensiones que se influencian mutuamente, es decir, un todo no escindido o política interméstica (Alons, 2007; Cox, 1981; Gourevitch, 1996; Foyle, 2003; Lasagna, 1995; Milner, 1997; Putnam, 1988).

Lo anterior se ha llevado a cabo a través de un análisis metateórico de fuentes literarias que se han referido a la temática respectiva de la política exterior chilena, desde la vuelta a la democracia. Aquel cuerpo ideológico se aborda mediante un recorrido histórico y cronológico de esta política exterior desde comienzos de la década de 1990 — en consideración de las bases e influencias propias del régimen autoritario anterior-, por medio de una concepción crítica de las Relaciones Internacionales, específicamente, la Teoría Crítica, y principalmente en su vertiente neomarxista, con autores como Cox, Van der Pijl, Berger y Leiteritz, Gill y Law, Linklater, Devetak, y Burchill, que hacen aportes como lupa de análisis conceptual, para introducirse a identificar aquellos elementos claves de la ideología subyacente a la política exterior de Chile.

En ese sentido se analizan características históricas y propias de este periodo de la política chilena como un todo articulado de lo interno hacia lo externo, y viceversa. Algunos de esos atributos nacionales, de acuerdo con la literatura, refieren a la esencia de apego al derecho internacional y al discurso democrático, como también a un estilo diplomático pragmático, a una valorización de relevancia al territorio soberano, y a la figura de la Presidencia de la República, entre otras características.

En definitiva, a estos elementos bibliográficos recientemente señalados se les preguntará permanentemente: ¿cuál ha sido la ideología que ha moldeado las prácticas en política exterior desde 1990, y respecto a qué objetivos y actores ha sido funcional? De esa forma, se permitirá comprender la ideología orgánica y hegemónica de las últimas tres décadas articulada con una hipótesis inicial:

Se entiende la política exterior de Chile, desde 1990, como una idea hacia la inserción en el sistema internacional para ser funcional a una hegemonía ideológica mundial, que somete y excluye otras visiones subalternas sobre las relaciones internacionales (Cox, 1981), en función, como ya argumentaba Marx, de mantener oculto el enriquecimiento económico, político, social y cultural de determinados grupos dominantes a nivel local, nacional e internacional, enmascarados por ideales que apelan a la libertad y la igualdad (Marx, 2014; Devetak, 2013). Esto conlleva crear o adoptar, específicamente en Chile, un corpus ideológico, en virtud de un modelo de política exterior acorde a los objetivos de estos actores, por medio de sus fuerzas sociales materiales, institucionales e ideacionales. 


\section{Marco teórico}

Para comenzar, es menester señalar que la Teoría Crítica de las Relaciones Internacionales aporta en este estudio, como lupa analítica general para introducirse a identificar los elementos ideológicos de la política exterior de Chile, relatada y analizada en la literatura acumulada en las últimas tres décadas. Esta vertiente de las Relaciones Internacionales plantea respecto a los elementos ontológicos básicos y generales de análisis, que debe tenderse a una resignificación y desnaturalización de las instituciones y estructuras clásicas como el Estado, la comunidad política y el orden internacional, para comprenderla en sus coordenadas de dominación y subordinación, y de inclusión y exclusión, en un contexto histórico que las determina, con el objetivo, no solo de comprender la organización de la realidad social, sino también en virtud de su transformación y emancipación (Del Arenal y Sanahuja, 2015; Devetak, 2013; Linklater, 1990).

De acuerdo con el objetivo que propone Devetak respecto al rol de la Teoría Crítica, la cual "problematiza y busca desmantelar formas de vida social que limitan la libertad humana" (2013, p. 140), se analizan las relaciones de dominación-subordinación, que se dan en un marco de convergencia ideológica entre la clase dominante transnacional y el Estado (Del Arenal y Sanahuja, 2015; Devetak, 2013). Esto último es considerado en este estudio a través de la descripción sobre cómo el Estado y las políticas transnacionales ejercen estrategias ideológicas para el consentimiento social.

En una estructura histórica existen mecanismos constituidos por reglas y normas que dan un orden hegemónico establecido, por medio - por ejemplo—, del contenido de las políticas exteriores de los países. De tal forma, se tiende a cooptar a las elites de los países periféricos, absorbiendo las ideas de sus actores subalternos contrarias a este orden establecido, con el fin de no dar espacios a posiciones emergentes y alternativas a la hegemonía dominante (Cox, 1981, 1983).

Estos aspectos teóricos ${ }^{[3]}$ para el análisis de la política exterior concernientes a este estudio permiten comprender la realidad internacional y sus impactos nacionales de una manera reflexiva, crítica y con mayor atención en los intereses, ideologías, valores, normas y prácticas de dominación y sumisión jerárquica de una clase dominante hacia una subalterna (Berger y Leiteritz, 2014; Cox, 1983; Devetak, 2013; Gill y Law, 1989; Van der Pijl, 1998). Lo anterior se entiende en el sentido que la Teoría Crítica y su corriente neo-gramsciana "ven la hegemonía en términos de clase — no de poder material de un Estado, como lo asume el realismo-y en un sentido que va más allá de lo estrictamente material o coercitivo” (Berger y Leiteritz, 2014, p. 12).

Por ende, el análisis de los aspectos ideacionales, y no solo materiales, sean de la realidad internacional, o nacional, se hacen cruciales a la hora de profundizar en las prácticas constitutivas, por ejemplo, de una política exterior, tal como propone Juliet Kaarbo (2003), al destacar la relevancia del rol que cumplen, por ejemplo, la identidad y las ideas en la conformación de las políticas exteriores, o como señala Valerie Hudson (2005), al enfatizar en lo multidimensional de la política exterior, en sus facetas ideacionales y materiales.

Cabe destacar a Robert W. Cox como uno de los principales exponentes de esta vertiente de la Teoría Crítica, donde plantea, reinterpretando a Gramsci ${ }^{[4]}$, la comprensión del Estado y su hegemonía como un centauro, es decir, mitad coerción, mitad convencimiento, o dicho de otra manera: el convencimiento de los dominados es la clave para el éxito de una hegemonía ideológica, económica y política. En palabras de Cox: "La represión está siempre latente pero solo se aplica en casos marginales o fuera de lo normal. La hegemonía es suficiente para asegurar la conformidad en el comportamiento de la mayoría de la gente la mayor parte del tiempo" (1983, p. 140).

En ese sentido, este estudio pretende identificar, analizar y criticar la estructura histórica hegemónica, plasmada en la política exterior de Chile. Cox básicamente define estructura histórica como

una combinación particular de modelos de pensamiento, condiciones materiales e instituciones humanas que tienen cierta coherencia entre sus elementos. Esas estructuras no determinan las acciones de la gente en ningún sentido mecánico, pero 
constituyen el contexto de hábitos, presiones, expectativas y limitaciones en los cuales dicha acción se desarrolla. (1981, p. 141)

Estas estructuras se basan en lo que Cox también rescata de Gramsci (Berger y Leiteritz, 2014; Cox, 1983; Devetak, 2013): las fuerzas sociales, las relaciones Estado-sociedad civil y el Orden Mundial, en donde se deben distinguir tres tipos de fuerzas en cada una de estos niveles de análisis: capacidades materiales, ideacionales e institucionales (Cox, 1981; Del Arenal y Sanabuja, 2015; Devetak, 2013), y que conjuntamente forman una ideología orgánica, como anteriormente se señalaba.

Y finalmente, esta ideología orgánica puede también homologarse o considerarse dentro de una de las nociones paradigmáticas y conceptuales de las Relaciones Internacionales, en las que Chile ha ido adhiriendo a través de sus prácticas, ideas e instituciones, sean de tipo realista o transnacionalista-neoliberal (Allan, 2001; Del Arenal y Sanahuja, 2015; Ruggie, 2009; Salomón, 2001), o ligándose a estrategias de inserción internacional como la autonomía relacional, el interés nacional económico o la cláusula democrática (Fuentes, 2014; Ovando y Aranda, 2013; Russel y Tokatlian, 2003; Witker, 2000, 2001).

\section{Marco conceptual}

Ya descrita la generalidad teórica en la que este estudio comprende las relaciones internacionales y de política exterior, cabe destacar cómo se comprende el concepto de ideología como tal. Este concepto es una categoría polisémica en la discusión de las ciencias sociales, las corrientes positivistas, historicistas, irracionales, marxistas, estructurales, posestructurales y posmodernas (Larraín, 2007, 2008, 2009, 2010). Sin embargo, se puede sintetizar en que la ideología, particularmente en su perspectiva neomarxista, o en su sentido positivo, como conjunto de ideas normativas y organizacionales de clase dialécticamente relacionadas con las prácticas sociales, en función de una nueva sociedad (Gramsci, 2005; Larraín, 2009; Lenin, 1961; Lukács y Sacristán, 1975).

La definición de Gramsci entrega una visión general de lo que se puede comprender como una ideología, no menos relevante para este estudio, por ser la génesis de la construcción teórica de la Teoría Crítica de las Relaciones Internacionales en esta materia conceptual, entendida como una ideología orgánica y un sistema de ideas o una concepción de mundo, presente en toda práctica social, capaz de organizar a las masas a través de orientaciones específicas de acción (Gramsci, 2005; Larraín, 2008). O también, como Cox (1981), establecería las Relaciones Internacionales como imágenes colectivas y pensamientos intersubjetivos de las fuerzas ideacionales de una estructura histórica en particular, articulada con fuerzas materiales e institucionales que presionan los comportamientos individuales y colectivos de las personas.

Bajo ese entendimiento dialéctico, Nicholas F. Martini destaca el rol de la ideología en la conformación de las políticas exteriores de las naciones, al definirla en aquel contexto como una

visión abstracta de cómo funciona el mundo y cómo las personas y los gobiernos deberían actuar dentro de este marco. Estas visiones sintetizan, en el sentido de que son más amplias, y de alcance más general, en lugar de abordar problemas o actitudes específicas. (2012, p. 11)

Cabe destacar que a pesar del poco uso de esta variable en el área, ya autores como Raymond Aron enfatizaron en que "las relaciones de un Estado con otro no son solo el reflejo de su poder relativo, sino también de las ideas, valores, y emociones de sus sociedades y de sus líderes" (1963, p. 117), donde se manifiesta atención a estos elementos no puramente materiales, sino también ideacionales.

Esto se refleja en estudios de las Relaciones Internacionales sobre periodos o temáticas clásicas, tales como la Guerra Fría (Parker, 2011), la Unión Soviética (Adomeit, 1980), la Liga de las Naciones (Egerton, 1991), y temas más actuales como el conflicto EE. UU y Siria (Gani, 2014), la política exterior estadounidense hacia Medio Oriente (Martini, 2015; Shlaim, 2011), la política exterior de Georgia (Oskanian, 2016), etc. Otras nociones al abordar la temática son los estudios de las políticas exteriores latinoamericanas, 
respecto a la convergencia entre las ideologías y el pragmatismo en el transcurso de las historias nacionales, fundamentalmente contemporáneas, de Gardini, Lambert, Fermandois, Raby, St. John, entre otros, en la obra Latin American Foreing Policies, compilado por Gardini y Lambert (2011).

$\mathrm{Si}$ bien estas conceptualizaciones en Relaciones Internacionales se sobreponen generalmente, y en cierta medida, a la dimensión ideacional a la dimensión de las prácticas sociales, actualmente, la política exterior de Chile se analiza preferentemente, desde perspectivas que enfatizan en el análisis los elementos y dimensiones materiales. Las estrategias comerciales y políticas a las que se recurre en determinados momentos históricos, en función al análisis del equilibrio de poder en la anarquía internacional, cuestiones de carácter geopolítico, o desde el debate sobre las ganancias absolutas y relativas de la cooperación (Correa, Salas, Soza-Amigo y García-Pinzón, 2015; Correa y García-Pinzón, 2012; Fermandois, 2006; González y Correa, 2005; Möller, Iduya y Thauby, 2007; Ross, 2005; Van Klaveren, 2011) son la base de los estudios en política exterior chilena, ligadas al paradigma racionalista de las Relaciones Internacionales.

No obstante, es posible abordar otros ámbitos propios de la política internacional de un país, en donde se problematice en niveles dialécticos entre lo ideacional y lo material, y asimismo, la ligazón histórica, entre la política doméstica y la política exterior (Alons, 2007; Colacrai y Lorenzini, 2005; Cox, 1981; Foyle, 2003; Gourevitch, 1996; Lasagna, 1995; Milner, 1997; Putnam, 1988).

Dicho eso, cabe mencionar que de acuerdo con ese marco conceptual, la política exterior como categoría de análisis se comprenderá bajo los lineamientos definidos por Tomassini (1989), quien la concibe como

un conjunto de Estados y otros agentes relevantes que interactúan dentro del marco de una estructura o régimen, en que cada una de esas partes ocupa un lugar determinado y, lo que es más importante, cumple una función a través de la cual se relaciona con las demás partes. (p. 332)

O como dice Lasagna, la política exterior

es aquella área de actividad gubernamental que es concebida como las relaciones entre el Estado y otros actores, particularmente otros Estados (pero no exclusivamente), en el sistema internacional, plan o programa diseñado a partir de objetivos o problemas y que sugiere una acción hacia actores externos. (1995, p. 389)

Además, se destaca también que, "por el mismo hecho de ser una actividad gubernamental, es necesario conocer no solo el escenario donde la política exterior es recibida, sino que también lo que ocurre en el proceso político doméstico nacional donde ella es generada" (Lasagna, 1995, pp. 389-390). Es decir, se comprenderá la política exterior como instrumento relacional entre actores en el escenario internacional, pero que nace como una política doméstica interna. Como establece Alons: "Para entender las preferencias de política exterior de un estado, necesitamos tener en cuenta sus consideraciones nacionales e internacionales” (2007, p. 211).

\section{Antecedentes Históricos de la Política Exterior de Chile}

Para comenzar dando un contexto general, es menester señalar que de acuerdo con M. Wilhelmy (1979), se establece que entre 1946 y 1970 se llevó a cabo en este país una política exterior conducida por una subcultura política dominante-moderada, que fue interrumpida en 1970 y 1973 por una subcultura política disidente de tipo revolucionario, que dio paso en 1973 a una subcultura política tradicionalista-integrista, que es desarrollada durante el periodo de la dictadura militar.

En el siglo XX, hasta el quiebre político de 1973, Chile era principalmente considerado como un país que apostó por la integración regional (Bernal-Meza, 2005), y que proyectaba una imagen de civilidad y estabilidad de las instituciones democráticas y su política exterior comprometida con el continente (Aranda y Riquelme, 2011; Muñoz, 1982; Wilhelmy, 1979).

En ese sentido, cabe mencionar también que a mediados del aquel siglo, hubo un relativo apoyo por parte de este país a la política de Sustitución de Importaciones (ISI) y la integración regional, como métodos de 
mejor adaptación al capitalismo internacional de la época, en función de la superación del subdesarrollo (Briceño, Quintero y Ruiz, 2013; Garretón, 2007), y para proteger y ampliar los mercados nacionales y la industrialización nacional y regional, reflejados, por ejemplo, en su participación y compromiso con el Pacto Andino (Aranda y Riquelme, 2011). El modelo ISI conllevó diversos beneficios para el desarrollo económico y social del país en los años de 1950 y 1960, pero "nunca pudo superar la falta de capital, el déficit fiscal, los desequilibrios en la balanza de pagos, las devaluaciones periódicas y un alto nivel inflacionario" (Fuentes, 2014, p. 142).

El golpe militar de 1973 manifiesta un hito transformador de la política exterior chilena del siglo XX. Este se caracterizó, entre otras cosas, por eliminar el modelo ISI y los esfuerzos de integración regional con base en el respeto del derecho internacional y las instituciones democráticas, por una postura radical de apertura hacia los mercados y economías mundiales desde un régimen autoritario-neoliberal (Muñoz, 1982; Aranda y Riquelme, 2011). A lo anterior se le agrega un aislamiento político y una vulnerabilidad externa de Chile en el escenario regional, reflejados, por ejemplo, en la inestabilidad en las relaciones vecinales con Perú, Argentina y Bolivia, y en la salida del Pacto Andino en 1976, en función de la apertura unilateral de la economía chilena de aquel entonces (Aranda y Riquelme, 2011; Flisfisch, 2011; Fuentes, 2014).

Heraldo Muñoz (1982) señala que aquellas características previas a la dictadura militar de Augusto Pinochet daban cuenta de una política exterior de Chile y su respectiva ideología orgánica, contenida dentro de un estilo civil-pragmático, liderado por diplomáticos de carrera que respetaban el derecho internacional e insertaban a Chile en la integración regional, aspectos modificados por un estilo pretoriano-ideológico y un carácter técnico y anticomunista (Aranda y Riquelme, 2011; Colacrai y Lorenzini, 2005). Estas características se abordan más adelante.

\section{La Política Exterior de Chile desde 1990}

Las políticas neoliberales se instalaron a comienzos de los años de 1990 a nivel global. Chile se establece como precursor en el continente de estas políticas, no solo desde la restauración de la democracia, sino también al implementar desde los años de 1970 una política exterior que continuó la senda comenzada por la dictadura militar, mediante la apertura económica al mundo, el ejercicio de libre mercado, el fomento de las exportaciones, la inversión extranjera, la disciplina fiscal y la iniciativa privada, condiciones que fueron también incentivadas por el Consenso de Washington (Fermandois, 2006; Fuentes, 2014; Ross y Leiva, 2016).

Por otro lado, el contexto posguerra fría, marcado por un escenario unipolar que se despojó del antiguo diseño global bipolar, y asimismo, un capitalismo en su fase posindustrial con su fundamento ideológico del fin de la historia, promulgado por el teórico Fukuyama y el Consenso Liberal de Bouzas (Ross, 2005), significaron la entrada de nuevas ideas, actores y fenómenos, primordialmente de tipo transnacional, en un espacio económico integrado, globalizado y comercializado por diversas empresas multinacionales (Aranda y Riquelme, 2011; Fuentes, 2014).

Esto, significaba que Chile en su contexto interno de recuperación de la democracia, y con el objetivo de reinserción y relegitimación internacional, debía acomodarse a las tendencias internacionales recientemente descritas, en función de acuerdos comerciales, políticos y financieros que dieran cuenta de sus características pragmáticas y de sello economicista en el aspecto ideológico, y posteriormente práctico (Fermandois, 2006; Fuentes, 2014; Portales, 2011; Ross, 2005; Van Klaveren, 2011; Wilhelmy y Lazo, 1997). Ergo, el enfoque chileno en política exterior desde el regreso a la democracia ha sido el de una economía-política liberal, construido desde la ideología neoliberal, y con el objetivo de apertura económica de los mercados al mundo (Bernal-Meza, 2005, 2016; Ross, 2005). 
Esto determina el destino del país a ser exportador de recursos naturales, concretizando un estilo que, a diferencia de otros autores, Cristián Fuentes (2014) concibe como una estrategia no pragmática, sino tradicional y economicista, que revela una concepción ideológica de clase dominante chilena, afín con una clase hegemónica internacional y trasnacional que se plasmaba en la época, para retornar a una consolidación de sustento monoproductivo de la economía interna basada en la exportación, faceta característica de los países suramericanos desde la época de la colonia (Flisfisch, 2011). Esto, además, daba atisbos del énfasis que se haría en la ideología neoliberal y el libre mercado, en contraposición a estrategias que promovieran una mayor simetría en el intercambio con los centros económicos a través de la industrialización de la economía interna, en complementación con la integración regional latinoamericana, como al menos lo ha planteado desde los 1990, la teoría neoestructuralista como alternativa al neoliberalismo (Sunkel y Zuleta, 1990; Telechea y Zeolla, 2014).

Desde estas premisas, los gobiernos de Chile buscan protagonismo regional por la vía de articular el nuevo escenario en torno a la construcción de regímenes internacionales. Así, se suscribe a las bases ideológicas coincidentes con la denominada autonomía relacional ${ }^{[5]}$, una expresión política de consenso liberal, en función de la gobernabilidad mundial y la cooperación internacional, mediada por la construcción conjunta de normas, identidades e ideas colectivas (Russell y Tokatlian, 2003). Se comienza a edificar la ideología orgánica: la arquitectura regional con base en principios como la cláusula democrática, la responsabilidad de proteger, la promoción del crecimiento con equidad, la inserción en regímenes de seguridad internacional, el respeto por los derechos humanos, la cooperación regional y la participación activa en el ámbito multilateral (Aranda y Riquelme, 2011; Ovando y Aranda, 2013; Portales, 2011; Witker, 2000).

Este consenso liberal en el que se inscribe la autonomía relacional invisibiliza las notorias dependencias económicas y políticas que Estados latinoamericanos, como el chileno, tienen de los centros económicopolíticos, puesto que omite las bases normativas de lo internacional, y el poder ejercido por las potencias. Y a pesar de las intenciones de sello constructivista de cooperación y participación activa de los Estados no hegemónicos (Ovando y Aranda, 2013), permite que mediante la sumisión a un sistema económico mundial integrado, pero desigual, se proyecte una imagen democrática y de autonomía política, cuando en realidad, se siguen sosteniendo las dependencias del pasado.

En aquel escenario

Chile se suscribe y aprueba la Declaración de Santiago sobre protección de la democracia, en el marco de la Organización de Estados Americanos (OEA) en 1991, y ha incluido en los acuerdos comerciales suscritos la denominada cláusula democrática [6], como ha sido el caso con el Mercado Común del Sur (Mercosur) y la Unión Europea. (Aranda y Riquelme, 2011, p. 19)

Y a la vez, se integra y pone en vigor a diversos acuerdos internacionales, como el Pacto Internacional de derechos civiles y políticos, el Pacto Internacional de derechos económicos, sociales y culturales, la Convención de Naciones Unidas contra la tortura, entre otros (Portales, 2011).

Aquello pone de manifiesto las ideas y discursos que circulaban en torno a la toma de decisiones, que se articulaban por una marcada necesidad de legitimación internacional, mediante la integración del discurso de la protección de los derechos humanos y las democracias liberales en el concierto internacional (Ross, 2005; Witker, 2001). Por ende, la cláusula democrática y su correspondiente discurso ha sido el instrumento rector de la política exterior de Chile en el ámbito multilateral posterior a Pinochet (Witker, 2000). Como consecuencia de esto, se establece la democracia como un fin, y no como un medio, el cual, en el caso de Chile en estas décadas, se ha constituido a través de objetivos y acciones de libre mercado, apertura comercial y participación multilateral (Aranda y Riquelme, 2011; Fuentes, 2014; Portales, 2011; Witker, 2000).

En suma, se podría conjeturar que los ideales liberales defendidos mediante los conceptos de autonomía relacional y cláusula democrática devienen en un idealismo que sacraliza la democracia procedimental, entendida como un marco de acción relacional que es construido por supuestos Estados libres y autónomos en 
igualdad de condiciones y poderes, o más bien poliarquías (Dahl y San Martín, 1997), en función a acuerdos principalmente de libre mercado.

Consecuentemente, se define a la democracia en el discurso, las instituciones y las prácticas, como símbolo de la ideología orgánica internacional, es decir, como la norma constitucional de las relaciones internacionales, a pesar de las grandes y actuales brechas entre naciones, y entre actores internos en los mismos regímenes nacionales. Además, esto tampoco considera que la democracia debería propiciar las condiciones de desarrollo como objetivo máximo, y no las condiciones actuales de (sub)desarrollo, debería ser de su interés propiciar la democracia como objetivo último.

Asimismo, en el ámbito económico se deriva en una apertura comercial a través de la estrategia del regionalismo abierto (Aranda y Riquelme, 2011; Bernal-Meza, 2016; Fermandois, 2006; Van Klaveren, 1997, 2011), el cual se comprende como "las acciones que están orientadas a incrementar la interdependencia y particularmente la cooperación económica entre los países de una región, en el marco de una tendencia sostenida hacia el libre flujo de los factores productivos sobre el nivel global" (Aranda y Riquelme, 2011, p. 19), lo que se refleja principalmente en Tratados de Libre Comercio.

En esos objetivos, la Dirección Económica de la Cancillería (Direcon) toma una gran relevancia dentro de este escenario, puesto que asume el rol de negociador de los tratados de complementación económica y libre comercio, siempre bajo la tutela del Ministerio de Hacienda (Fuentes, 2014), hecho que es explicado como parte de la modernización de la Cancillería en los años de 1990 (Van Klaveren, 2011). En ese sentido, Fermandois (2006, destaca la relevancia que han tenido, no solo los actores diplomáticos clásicos de la Cancillería en materia de política exterior, sino también, el ya nombrado Ministerio de Hacienda, la Academia, los presidentes del Banco Central, y la denominada cooperación Estado-empresarios al conformar una estructura histórica que conduce la ideología orgánica de la política exterior de Chile desde 1990.

Esto lleva a comprender que en política exterior debe existir cooperación regional, siempre y cuando, se permita la apertura constante a que se integren nuevos miembros de otras latitudes, en función de la liberación del comercio a nivel global (Van Klaveren, 1997). La integración latinoamericana, entonces, se vio sometida a una intensa crítica como estrategia internacional, que afectó a los procesos de regionalización y la política de inserción internacional de Chile durante la transición democrática (Fuentes, 2014), deviniendo en la elección del "carril múltiple" de negociaciones internacionales, en la búsqueda de socios comerciales y políticos (Portales, 2011).

Lo anterior, finalmente se concretiza mediante una apertura internacional unilateral por parte de Chile con negociaciones políticas y económicas multilaterales, que le permite a la política exterior chilena, desde una perspectiva basada en el realismo político subregional (Witker, 2000) y el pragmatismo neoliberal, mantener negociaciones con todos los socios que considerara necesarios, productivos y naturales para su desarrollo económico-comercial (Aranda y Riquelme, 2011; Bernal-Meza, 2016; Van Klaveren, 2011).

En consecuencia, se consolidó un pensamiento transnacionalista-neoliberal en las materias principalmente económicas, en las que ha tenido un énfasis general en lo referente a política exterior posdictadura militar. Esta tendencia ideológica contiene en su esencia una visión utilitarista en virtud de los costos y beneficios en las relaciones internacionales, adoptando el regionalismo abierto y la cooperación internacional como estrategias transnacionales, con base en la perspectiva neoliberal de las Relaciones Internacionales (Allan, 2001; Del Arenal y Sanahuja, 2015; Ruggie, 2009). Estas estrategias se diferencian de las prácticas realistas o neorrealistas en el ámbito político vecinal, al relacionarse, más bien, con temas de soberanía e integridad territorial, subordinando el ámbito económico-comercial a estos dogmas.

En el primer caso, y siguiendo la teoría transnacional de las Relaciones Internacionales, las estructuras institucionales modificarían los comportamientos de las tomas de decisiones, en respaldo a la concepción ideológica de la paz democrática entre naciones, o la paz perpetua de tipo kantiano, lo que permite una cooperación internacional — fundamentalmente comercial y de libre mercado- en la ausencia de la guerra. Y en materia geopolítica — en este caso vecinal y transfronteriza—, se sigue sosteniendo una vertiente realista o 
neorrealista, en la que permanece la actitud desconfiada, antropológicamente egoísta y basada en el principio de autoayuda (Allan, 2001; Del Arenal y Sanahuja, 2015; Doyle, 1997; Gobetti, 2009; Ruggie, 2009), aspectos diferenciales en la política exterior chilena, que se retomarán más adelante.

\section{Política Exterior de Chile en el Siglo XXI}

El contexto posterior al 11 de septiembre de 2001 elevó a Asia como el principal socio de países como Chile dentro del concierto suramericano (Maira, 2011). Este acercamiento a Asia refleja la denominada "alma de Chile", que Fermandois (2006) define como el apego chileno constante, de estar a tono con los cambios y equilibrios de poder a nivel mundial, es decir, en función del mantenimiento de un estatus quo internacional, lo que genera como consecuencia, la imposibilidad de ser percibido como un país disidente a la ideología hegemónica internacional.

Chile, en sus objetivos de prioridad económica-comercial, ha consolidado relaciones fructíferas más con potencias mundiales o economías emergentes en el globo que con sus pares regionales, lo que devela sus intereses ideológicos en política exterior. Eso se refleja en que el $75 \%$ de sus exportaciones se concentran en Estados Unidos, la Unión Europea y Asia-Pacífico, y el 90 \% de las inversiones de extranjeros en Chile proviene de aquellas latitudes (Van Klaveren, 2011). Esto se produce en el contexto de mayor auge en las relaciones diplomáticas entre Chile y Estados Unidos (Fermandois, 2006), las cuales se cristalizan en el Tratado de Libre Comercio entre ambos países en el año 2004, al igual que se hizo con Canadá en el año 1996, y con la Unión Europea en el 2002, lo que, a pesar de su relevancia para el país, ha sido superado por China y las potencias del Asia-Pacífico (Van Klaveren, 2011; Wilhelmy y Lazo, 1997).

De acuerdo con Aranda y Riquelme (2011), la política exterior de Chile se ha mantenido en un estilo, objetivos y prioridades estables desde la vuelta a la democracia, a pesar del cambio de coalición de gobierno en 2010, en donde el consenso político y la cooperación entre actores internos fueron algunas de las características de la denominada política de Estado en referencia a las relaciones exteriores de Chile. Es aquella continuidad la que Fermandois (2006) define como una tradición política e histórica en Chile, la que ha llevado que históricamente este país mantenga continuidad en aspectos como la institucionalidad, coaliciones de gobierno, cultura política, oposición y objetivos en política exterior. Como señala Araya (2017):

(...) sus elites entienden la política exterior como un área de consensos tácitos y no un área de competencia política; pero ha tenido como contraparte dificultades evidentes en la capacidad del Estado para enfrentar los cambios en el sistema internacional y sigue siendo un área gris en relación con el escrutinio público o la participación ciudadana en contextos de demandas sociales por mayores niveles de transparencia y participación (p. 74).

En suma, los gobiernos de la Concertación y el gobierno de derecha de Sebastián Piñera (2010-2013) han priorizado discursivamente la integración latinoamericana, pero con una esencia y estilo pragmático, en donde los objetivos comerciales y la apertura a las economías mundiales, y fundamentalmente, hacia las potencias económicas, han sido los reales fines e intereses en política exterior, al igual que lo que el segundo gobierno de Michelle Bachelet (2014-2018) mantuvo en su mandato. Por lo tanto, la visión estratégica en política exterior ha sido compartida entre los gobiernos y las oposiciones, es decir, entre los dos grandes conglomerados políticos de la elite chilena, que han coincidido por más de veinte años en cómo llevar a cabo la inserción internacional de Chile, sin grandes divergencias (Aranda y Riquelme, 2011; Araya, 2017; Fermandois, 2006). 


\section{Política Regional y Regionalismo Abierto: transnacionalismo/neoliberalismo en respuesta al neorrealismo}

Desde la vuelta a la democracia y mediante los gobiernos de la Concertación, Chile apuesta a una inserción internacional integrativa, pero de carácter multilateral, al hacer énfasis en Latinoamérica y los foros internacionales de la región (Aranda y Riquelme, 2011; Fuentes, 2014; Ross, 2005): una integración en clave no utópica (Van Klaveren, 2011), y como una política nacional integrada de carácter suprapartidista y pragmática (Araya, 2017; Wilhelmy y Lazo, 1997). Aquello, por ende, da cuenta de una política de elites nacionales cohesionadas en una estructura histórica y en una ideología orgánica, en virtud de intereses propios y de clases trasnacionales e internacionales.

La política regional chilena se ha querido caracterizar por una identidad latinoamericana que comparte una historia, una cultura, intereses y objetivos comunes, pero sin descuidar su política de apertura al mundo y desarrollo nacional (Aranda y Riquelme, 2011). Evidencia discursiva y práctica de una política exterior que no pretende ejercer una integración regionalista bajo las ideas de reciprocidad y flexibilidad, sino más bien, bajo identidades e ideas pragmáticas reflejadas en las acciones estratégicas del regionalismo abierto y el multilateralismo económico (Portales, 2011), y que para el reconocido internacionalista Alberto Van Klaveren (2011) responde a una estrategia pragmática y realista por parte de Chile.

La integración regional se ha constituido en el discurso declarativo de la política exterior chilena, pero de forma oscilante e interrumpida en sus acciones (Jenne y Briones, 2018). No obstante, se ha declarado la necesidad y la voluntad de aquella prioridad regional, en donde el marco del entendimiento entre países de la región es clave para la cooperación concretizada en proyectos conjuntos, es decir, anteponer el principio de respeto a las diferencias político-ideológicas (Ross, 2005) en el contexto de "paz perpetua" (Doyle, 1997; Gobetti, 2009), pero con un denominador ideológico en común: las ganancias absolutas y compartidas dependiendo el caso - en la economía de libre mercado.

Por lo tanto, este regionalismo abierto, que caracteriza hasta la actualidad a la política exterior de Chile, permite que la prioridad regionalista no sea excluyente con acuerdos superpuestos con distintos espacios, con el objetivo principalmente comercial de exportación hacia países no necesariamente de la región (Van Klaveren, 1997; Witker, 2000), lo que hace converger la visión del regionalismo latinoamericano con el regionalismo hemisférico (Van Klaveren, 1997) y el interregionalismo (Unión Europea y Asia-Pacífico, particularmente).

Ya mencionado el estilo pragmático adquirido por la política exterior de Chile, hay que hacer hincapié en los fines e intereses que son orientadores de estas formas de inserción internacional y vínculo exterior, los cuales tienden a posibilitar y consolidar una estabilidad en la región para posicionarse como puente comercial y económico con el mundo global, y principalmente entre el Océano Atlántico y el Océano Pacífico (Aranda y Riquelme, 2011; Wilhelmy y Lazo, 1997; Witker, 2000). Además, contribuyen a fomentar la competitividad en la región, en función de abrirse a otros mercados más poderosos a través de tratados de libre comercio, tal como lo ha hecho Chile con México, la Unión Europea, Estados Unidos, Colombia, Ecuador, Perú, y países del Asia-Pacífico, entre otros (Ross, 2005; Van Klaveren, 1997; Van Klaveren, 2011).

A pesar del constante discurso político de los cancilleres que destacan la relevancia del valor agregado en las exportaciones prioritarias hacia Suramérica, existía en 2009 un $9 \%$ de exportación de manufacturas industriales, mineras y agropecuarias chilenas hacia la región: la principal fuente de exportación corresponde, y sigue siendo, hacia países extranjeros desde el continente latinoamericano, esencialmente europeos, norteamericanos y asiáticos (Aranda y Riquelme, 2011; Fuentes, 2014; Wilhelmy y Lazo, 1997). De esa forma, se comprueba que, en los ideales chilenos de política exterior, la región latinoamericana no es prioridad (Flisfisch, 2011), sino que más bien, la dimensión integrativa en política regional es más declarativa que concreta en políticas (Jenne y Briones, 2018). 
Cabe destacar que para Iván Witker (2000), el concepto de regionalismo abierto carece de contenido teórico, lo que ha llevado a que las decisiones de las autoridades sean más bien ambiguas, a diferencia de cuando se ha operado la política exterior con base en el concepto de interés nacional. Esto se evidencia, por ejemplo, en el caso Chile, respecto al denominado matiz chileno sobre el regionalismo abierto, el cual no prioriza por la geografía y la cultura en común con Suramérica o Latinoamérica, sino por su interés nacional de tipo comercial y económico en general, lo que se acerca más a un regionalismo abierto, más cercano a la APEC (Ross, 2005; Witker, 2000).

Esto consiste en desentrañar el interés nacional a partir del cuestionamiento de la antropomorfización del mismo (Weldes, 2009), o la tendencia propia de las Relaciones Internacionales predominantes, que apuntan a que el Estado se concibe como un ente con sus propios valores e intereses inherentes, los que, sin embargo, corresponden a los valores e intereses de sus representantes o encargados de la toma de decisiones en una coyuntura determinada. Tal como ocurre con la política exterior de Chile a comienzos de los 1990, en el momento en que la Cancillería toma una dirección comercial, más que política, deviene, por tanto, en una diplomacia empresarial dirigida por la Direcon (Fuentes, 2014; Ross, 2005). En concreto, se configura el denominado interés nacional, que no es más que el interés de esos funcionarios en dicha coyuntura (Burchill, 2005). Esta tendencia se expresa en el axioma "lo que favorece al estado, favorece a la nación" (Weldes, 2009), lo que es particularmente notorio cuando se trata de una política exterior comercialista al extremo.

Esta perspectiva ideológica chilena sobre las Relaciones Internacionales considera al Estado como un ente no problemático, en una coyuntura marcada por el regionalismo abierto, matizado por las características propias de los gobernantes chilenos. Aquello, entonces, no ayuda a definir con propiedad, quién enuncia y delimita el interés nacional, en torno a la diversificación de las exportaciones y las firmas de Tratados de Libre Comercio como la estrategia a seguir, salvo el Estado, entendido como una entidad única, con su identidad propia y un conjunto de intereses determinados. Desde esta perspectiva, se opacan los procesos sociales que ocurren dentro de las sociedades nacionales, y quienes podrían contribuir a debatir el contenido particular del interés del Estado, ya sean comunidades epistémicas afines o críticas del poder, funcionarios representantes de las cancillerías, sociedades civiles, etc.

Con todo, la política exterior pragmática de Chile, aunque presente acción regionalista, la acota hacia fines comerciales y económicos en función de los beneficios propios y trasnacionales, que consideran que en la región se ha debatido sobre la integración multidimensional (Bizzozzero, 2007), o posliberal (Sanahuja, 2012), encerrados en la necesidad de establecer un sistema de integración compatible y estimulante de la competencia, el desarrollo tecnológico y la apertura global de las economías.

\section{Plataformas multilaterales}

En ese contexto, Chile, como miembro asociado desde 1996 a Mercosur, apostó hacia una constante participación de los bloques y procesos de integración regional, para, de tal forma, estar conectado y acomodado con la nueva realidad económica mundial (Aranda y Riquelme, 2011; Fermandois, 2006; Van Klaveren, 1997). Chile establece con Mercosur "una política de dos caras, pero no hipócrita" (Fermandois, 2006, p. 96). La cancillería, mediante documentos oficiales, ha expresado la relevancia de Mercosur para este país, y la voluntad del mismo por seguir participando en todos los órganos que correspondan al interior de Mercosur, pero solo estableciéndose como el cuarto socio de Chile, después de Estados Unidos, China y Japón (Aranda y Riquelme, 2011; Fuentes, 2014), lo que evidencia la política de dos caras que propone Fermandois, y que se puede homologar con la Comunidad Andina de Naciones, donde también solo es miembro asociado.

Sin embargo, aquella vocación integracionista chilena no es rescatada en su espíritu original, sino más bien, como se ha explicado anteriormente, se constituye como una doble estrategia discursiva, por un lado, la cual eleva relatos de integración regional como prioridad internacional, y por otro, mediante acciones en 
las plataformas internacionales, para vislumbrarse como actor comprometido con el continente, pero siempre por medios incompletos (Jenne y Briones, 2018).

En ese contexto, este país, al reinsertarse en el sistema internacional, integra el Grupo de Río, donde llega ocupar la Secretaría Pro Tempore en el año 2010. Asimismo, otra participación de Chile en organismos multilaterales es la membresía plena en la Unasur, desde su entrada en vigor desde 2011, o ya desde su ratificación en septiembre de 2010 (Aranda y Riquelme, 2011; Van Klaveren, 2011). Bajo la institucionalidad de Unasur, Chile ha demostrado su mayor participación regionalista en su política exterior, membresía que no obstaculizó el estilo pragmático y la metodología del regionalismo abierto y el multilateralismo como medios para la acción internacional de este país (Aranda y Riquelme, 2011; Van Klaveren, 2011); percepción positiva de Unasur, que no se consideraba peligroso para las principios ideacionales, discursivos y prácticos de la política exterior chilena, aspecto que se sabía de antemano por la participación de este país en la organización regional, y que asimismo, motivó su integración (Oyarzún, 2017).

\section{Política vecinal}

$\mathrm{Al}$ interior de la política multilateral chilena existe un importante vínculo de relaciones de carácter regional, fundamentalmente con los países vecinos, basado en el gran influjo de inversiones chilenas en naciones como la peruana y la argentina (Aranda y Riquelme, 2011), lo que evidencia el acento comercial y económico de las relaciones vecinales de la política exterior de Chile.

En este marco, los corredores bioceánicos toman gran importancia simbólica y discursiva en las relaciones diplomáticas con los vecinos del país chileno, puesto que aquellos canales son parte principal de los procesos de conexión migratoria y comercial con aquellos países (González, Barra e Iturra, 2017), en donde Chile establece complementación en áreas estratégicas como la energía, la minería, el turismo y la infraestructura en función del desarrollo compartido (Aranda y Riquelme, 2011; Van Klaveren, 2011).

Específicamente con Argentina, las relaciones bilaterales en el contexto de reinserción del país en el mundo, y en el fomento de los valores democráticos en búsqueda de la concertación regional, se caracterizaron desde la vuelta a la democracia, en una continuidad de cooperación en términos políticos, comerciales y físicos (Witker, 2000), que ya se habían comenzado a ejercer desde 1985, por medio de la Comisión Binacional Permanente, plasmada en los años de 1990 en la resolución de los diversos temas limítrofes pendientes (Portales, 2011; Ruz, 2011; Van Klaveren, 2011).

Se construyó un sello en torno a un vínculo integrador en términos fundamentalmente de intercambios económicos y de inversiones, acuerdos y cooperación transfronteriza, tecnológica, científica y de turismo, entre ambos países, los cuales han tenido prioridad para Chile en las últimas tres décadas, ya que por medio de múltiples acuerdos bilaterales, como el simbólico Tratado de Maipú de Integración y Cooperación, se vive actualmente un etapa consolidada y fortalecida en las relaciones bilaterales en ámbitos políticos, económicos y sociales (Portales, 2011; Ruz, 2011; Van Klaveren, 2011). Los roles chileno y argentino en la región se han caracterizado por constituirse como actores de consenso, como de voluntad de protagonismo en la región a través de un liderazgo político regional, tal como se señalaba anteriormente, en relación con el estilo compartido de liderazgo regional de ambas naciones (Colacrai y Lorenzini, 2005).

Respecto a las relaciones vecinales más complejas - y por momentos, más conflictivas-, sobre todo en los últimos años, han sido las emprendidas con Perú y Bolivia, vínculos marcados por los problemas limítrofes y diplomáticos (Portales, 2011). Particularmente con Perú, ha predominado un intento de política exterior de cuerdas separadas, en donde se han incentivado y extendido los acuerdos comerciales y activos chilenos en el Perú, y al mismo tiempo, han permanecido conflictos diplomáticos de carácter limítrofe (Portales, 2011). Se trata de los experimentados en la demanda ante la Corte Internacional de Justicia de la Haya, concluida el 
año 2014, en gran parte, a favor de la demanda peruana ante el Estado de Chile, sin perjudicar los vínculos económicos, turísticos, migratorios y comerciales (Van Klaveren, 2011).

Específicamente con Bolivia, se han establecido acuerdos comerciales, políticos, transfronterizos y sociales, desde los años de 1990, pero sin restablecer las relaciones diplomáticas (Portales, 2011; Van Klaveren, 2011), lo que responde a una relación de doble asimetría bilateral, en un diálogo de sordos entre ambos países, donde Bolivia aspira a la salida soberana al mar como objetivo diplomático elemental, y Chile enfatiza en los aspectos comerciales, por lo que se produce una frustración bilateral por la incompatibilidad de la prioridad de agenda en las relaciones bilaterales (Ross y Leiva, 2016).

Es menester señalar que Bolivia ha experimentado grandes cambios a nivel de Estado en materias de descentralización y deselitización, pero Chile lo sigue tratando como si fuera un país unificado, centralizado y no plurinacional, obviando las autonomías propias de las regiones, por ejemplo, transfronterizas bolivianas (Bernal-Meza, 2016; Ross y Leiva, 2016). Aquello es reflejo de una política realista, economicista y tradicional del gobierno central chileno, que responde a un imaginario ligado al conflicto, la seguridad y el crecimiento económico, que trata de impulsar las relaciones ligadas con Tratados de Libre Comercio y operaciones de inversiones poco exitosas con Bolivia (Ross y Leiva, 2016), desestimando la existencia de temas pendientes en torno a la reivindicación marítima boliviana.

Las concepciones centralistas en política exterior han situado en segundo plano el tema fronterizo y las relaciones paradiplomáticas con los vecinos, principalmente del norte, en su vertiente político-histórica, dado que la cooperación, integración y crecimiento por esa vía colisiona con los intereses realistas de soberanía e integralidad territorialidad (Ovando y Ramos, 2016). Esto posiciona, como consecuencia, a los empresarios como actores principales en las relaciones bilaterales (Ross y Leiva, 2016), y los imaginarios geopolíticos de seguridad y defensa nacional, como prioritarios a la hora de vincularse en términos histórico-políticos.

En suma, ¿ por qué las autoridades chilenas han mantenido, respecto a su integración con el continente, un discurso de apertura a la globalización, basado en la ideología transnacional de las Relaciones Internacionales y, por otro lado, una postura realista o neorrealista, en lo que refiere a los vínculos con Perú y Bolivia?

Principalmente, se puede responder esta interrogante por el pragmatismo tradicional chileno en materia diplomática y de relaciones exteriores, en donde el contexto mundial, continental y vecinal, son estudiados en función a la realidad de las fuerzas materiales, institucionales, e ideacionales de la política interna y sus respectivas necesidades de elite. Es decir, para el Estado chileno posdictadura militar, ha sido esencial mantener una figura camaleónica al momento de escoger las estrategias, los discursos y las prácticas en su inserción y vínculo internacional, lo que se manifiesta en una esencia como un país moderno que interactúa permanentemente con el primer mundo en clave transnacional y neoliberal.

Pero, asimismo, su agenda con la mayoría de los países vecinos se mantiene marcada por los conflictos del pasado (Araya, 2017), bajo los clásicos cánones geopolíticos de seguridad, defensa y soberanía territorial westfaliana, estrategias realistas y neorrealistas con sus vecinos principalmente del norte, con el objetivo de mantener el statu quo político, geográfico y económico del mapa suramericano.

\section{Ideología Orgánica: estructuras y fuerzas sociales de la política exterior de Chile}

Para seguir respondiendo a la pregunta sobre cuál ha sido la ideología de la política exterior de Chile desde 1990, los postulados de Myriam Colacrai y María Elena Lorenzini (2005), que hacen referencia a los factores internos de la política exterior, la identidad nacional y su imagen autopercibida, aportarán convergentemente con la ya analizado.

Las autoras definen la esencia de la identidad nacional chilena, reflejada en la política exterior histórica del país, en características constituidas por una ideología que se apega la estabilidad política e institucional como 
bienes supremos de la nación, acompañados por los rasgos nacionalistas en torno a la cuestión territorial, y presidencialistas en función de una dirección de la política exterior acotada en la máxima autoridad republicana.

Establecen, entonces, cinco fuerzas profundas claves de la política exterior de Chile, que se encuentran explícitas en el recorrido histórico y bibliográfico de este estudio, y que, por tanto, convergen de la siguiente manera:

- El apego a los procesos democráticos: ligado inmediatamente con aquella persistente búsqueda de prestigio internacional y la imagen de Chile en el mundo, que se expresa, en este caso, como una estrategia nacida desde el idealismo y el constructivismo, reflejada en el marco de los valores democráticos que sostienen la autonomía relacional (Russell y Tokatlian, 2003) y las mutaciones del interés nacional ajustadas a esta (Witker, 2000).

Estas características ideológicas de Chile responden a una identidad nacional que pretende ser erigida como un modelo a seguir, o más bien, como un ente superior en la región, el cual es capaz de adaptarse a los procesos hegemónicos mundiales, con el objetivo de beneficiarse de los mismos y, de tal manera, posicionar a una elite política nacional como referente en la región y en el mundo, para consolidar sus poderes discursivos, ideacionales, institucionales y económicos, en la libertad de movimiento que aquel prestigio les brinda. También es coincidente con la esencia legalista que propone Pilar Álamos (1999) de la política exterior de este país, fundada en los principios de Andrés Bello, que impregnó históricamente el quehacer internacional de esta nación.

En definitiva, es una adhesión irrestricta de la democracia liberal y del derecho internacional, como formas únicas de organización política nacional, aceptables entre Estados en el contexto de la anarquía internacional. Es decir, una estrategia transnacionalista de Relaciones Internacionales (Allan, 2001; Del Arenal y Sanahuja, 2015; Ruggie, 2009; Salomón, 2001), en virtud de promover una forma ideológica de comprender el nuevo orden mundial, que afirma que, mediante la interdependencia económica y el libre mercado, sumados a los derechos civiles y políticos, se deben propiciar las bases de una sociedad internacional pacífica y democrática (Allan, 2001; Del Arenal y Sanahuja, 2015; Ruggie, 2009).

- El papel protagónico de lo territorial: para mantener el statu quo con sus vecinos entorno a la defensa del territorio, negando temas pendientes, bajo el principio de integridad territorial, defensa y seguridad nacional fundamentado para Chile, en su apego tradicional a los tratados internacionales, principalmente de índole geográficos, aferrándose fuertemente al principio pacta sun servanda, en contraposición a lo que hoy para Bolivia es el promissio est servanda (Orias, 2015).

En esa lógica, Chile en su argumento ceñido al derecho internacional, pretende mantener el control de los recursos naturales y geográficos, en virtud de beneficios económicos, como ocurre esencialmente en materia minera y marítima, a través de políticas extractivistas y monoproductivas, que emergen desde el reconocimiento internacional de dominación económica ante los centros internacionales y trasnacionales. Por ejemplo, la vinculación con la región del Pacífico, fundamentada en las características geográficas de Chile, y el objetivo claro propuesto desde la época de Diego Portales, de ser un país marítimo que posea la hegemonía, comercial y marítima en general, del Pacífico suramericano (Álamos, 1999) es una evidencia del apego territorial de este país.

En ese sentido, las últimas décadas se han adecuado de manera pragmática para mantener el poder político a nivel nacional, geopolítico a nivel vecinal y económico comercial a nivel continental e internacional, donde sus principales fuentes ideacionales son el sentido de superioridad nacional ante sus vecinos y su posición de dominado por los bloques ideológicos transnacionales, en una lógica de doble asimetría (Ross, 2005).

En definitiva, si lo comprendemos desde la teoría de las Relaciones Internacionales, las ideas de apego al territorio se comprenden desde el realismo político, es decir, son estato-céntricas, antropológicamente pesimistas, defensoras del mantenimiento del equilibrio de poderes, y están en búsqueda de prestigio y gloria (Allan, 2001; Del Arenal y Sanahuja, 2015; Ruggie, 2009), aunque con la especificidad que se ejerce como una 
estrategia realista para fines transnacionalistas, lo que hoy podemos comprender como parte de una síntesis racionalista.

- Equilibrio de poder e influencia regional: en este periodo, esta última se refleja en el apego a la estrategia de regionalismo abierto en materia económica, en donde se aspira a conservar, no solo un equilibrio de poder económico regional, sino también internacional y transnacional, en virtud de las tendencias afines a clases dominantes extranjeras. Y, por otro lado, mantener un statu quo en lo referente a lo geopolítico, reflejado en la integridad de soberanía territorial respecto a aspiraciones vecinas.

Cabe destacar que las principales ideas y discursos que sostienen las estrategias de equilibrio de poder y mantenimiento del statu quo son relativas a la comprensión de la posición intermedia de Chile en la correlación de fuerzas hegemónicas en el mundo, de una manera conformista que acepta la dominación de los bloques transnacionales en función del beneficio económico-político para sus gobernantes.

Esta característica valórica y estratégica de esta política exterior es definida por Pilar Álamos (1999) como la única fuerza ideacional que permite el abandono circunstancial de los principios democráticos y legalistas anteriormente descritos, por lo que permite la legitimación de la fuerza militar, cuando el equilibrio de poderes lo demande.

- El presidencialismo marcado en la conducción de la inserción internacional de Chile: en este periodo ha sido acompañado por un fuerte consenso de la elite política nacional en materia de política exterior. La idea principal que sustenta la "política de Estado", que une a oposiciones con oficialismos, ha sido, fundamentalmente, la idea de interés nacional, la cual consiste en entender que los fines políticos de la nación benefician a todos los chilenos. Sin embargo, al mismo tiempo, la esencia de aquella comprensión ideacional oculta las identificaciones de clase, propias de dos conglomerados que evalúan las ganancias políticas como económicas en la inserción internacional de Chile, donde operan como una estructura histórica interna con base en consensos de elite (Araya, 2017).

Esta realidad de convergencia y unidad de las elites en el poder, bajo el simbolismo de la conducción monopolizada de la presidencia de la república, remite a la necesidad de la clase dominante nacional, internacional y transnacional, de expresar una fuerza material, ideacional y discursiva, lo suficientemente fuerte para legitimarse en aquel papel de poder absoluto, para absorber ideas contrahegemónicas o subalternas (Berger y Leiteritz, 2014; Cox, 1983). En concreto, la clave para desarrollar y establecer una ideología orgánica única en materia de política exterior refería a la posibilidad de consentimiento popular, el cual, en este caso, fue aprehendido por medio de la característica histórica chilena de apego hacia la figura fuerte del líder republicano.

- El estilo diplomático civil-pragmático: que se moldea a todo contexto en virtud de los intereses de determinadas elites, las cuales hoy, y en las últimas tres décadas, han estado a disposición de los controladores de los mercados internacionales y transnacionales. Aquí se hace explícito que el pragmatismo, expresado como estrategia camaleónica, es, en esta ocasión, economicista y ortodoxo (Fuentes, 2014; Ross, 2005), y se adecúa a los conceptos de autonomía relacional de tipo neoliberal, y de interés nacional económico (Ovando y Aranda, 2013; Witker, 2000), que da pie a un cuerpo teórico-ideológico que le permite a Chile adecuarse a la correlación de fuerzas hegemónicas a nivel internacional.

Pero, si bien este estilo diplomático chileno se basa principalmente en la concepción de ganancias absolutas y compartidas en el plano económico a nivel intercontinental y transnacional, también se manifiesta en su vertiente geopolítica a nivel vecinal y transfronterizo, al cambiar camaleónicamente las estrategias de acuerdo con el tipo de interés nacional que predomine.

Respecto a esta última fuerza profunda, se ha señalado anteriormente que ya en 1988, es Heraldo Muñoz quien considera que en los periodos democráticos chilenos existe un estilo civil-pragmático que promueve el apego a ideales, identidades, discursos y acciones relacionadas con el respeto por el derecho internacional y reconocimiento práctico de las realidades distributivas del poder en el concierto internacional (Colacrai y Lorenzini, 2005). Esto es un claro anuncio de una convergencia institucional, material e ideacional 
camaleónica, que ha construido un corpus ideológico o una ideología orgánica, que es capaz de organizar y establecer una estructura histórica cohesionada y unificada durante casi 30 años.

Asimismo, como se señalaba al comienzo de este artículo, Manfred Wilhelmy (1979) funda los conceptos de subculturas políticas para caracterizar las formas ideacionales y de acción de la política exterior de Chile en los siglos XX y XXI. En el caso de la política exterior, considerada por este auto como subcultura dominantemoderada, da cuenta de ideales, identidades y discursos cercanos a las aspiraciones de países desarrollo y pro statu quo internacional, con una perspectiva legalista de apego irrestricto al derecho internacional y promoción de los regímenes democráticos, lo que se apega a la actual expresión de la subcultura política exterior (Colacrai y Lorenzini, 2005).

A partir de estas creencias, ideales, identidades y discursos, surge una amalgama de estrategias y acciones, expresadas a lo largo del trabajo, de la política exterior de Chile desde 1990 hasta la segunda década del siglo XXI. Sea en clave de fuerzas profundas, fuentes históricas, subculturas políticas, estilos, o proposiciones de acción, subyacen en una visión de mundo que constituye una ideología orgánica que ha sido capaz de movilizar fuerzas y estructuras sociales, en función de beneficios determinados, para actores determinados.

\section{Conclusiones}

En suma, la política exterior de Chile ha sostenido no solamente desde el comienzo del proceso democrático en 1990, sino también desde la dictadura militar, un énfasis en el ámbito comercial y económico, con base en un estilo ideológico pragmático que se expresa principalmente en un comportamiento camaleónico y, a momentos, tradicional, realista y ortodoxo, como se expresa en la dimensión vecinal. Las políticas establecidas desde el Ministerio de Relaciones Exteriores, la Dirección, el Ministerio de Hacienda, la academia afín al poder, el empresariado transnacionalizado, o desde la Presidencia de la República, han desplegado un regionalismo abierto y un multilateralismo que se ha distanciado de estrategias para superar el subdesarrollo de forma concreta, mejorar los términos de intercambio en función de una menor asimetría con los centros económicos mundiales y un desarrollo económico no dependiente de la exportación de recursos naturales, en complementación con una integración regional recíproca y flexible, siguiendo el pensamiento internacionalista original latinoamericano (Bernal-Meza, 2005).

Por lo tanto, la política exterior de Chile ha estado elementalmente enfocada en el crecimiento económico nacional, o más bien, en determinadas elites nacionales, a través de políticas internacionales y transnacionales, originadas en los consensos políticos entre coaliciones de derecha y de centro-izquierda, en donde lo prioritario ha sido los intereses de los sectores privados de inversiones, en virtud de un progreso económicosocial al estilo neoliberal, que solo ha aspirado a mejores formas de equidad social mediante la demanda de oferta de trabajo y revitalización de los comercios internos como consecuencia de sus políticas internacionales, reflejadas principalmente en Tratados de Libre Comercio y una tenue influencia regionalista en la política vecinal-comercial (Flisfisch, 2011).

La política exterior de Chile se ha adecuado a las nuevas imposiciones endógenas y exógenas de la economía y la política mundial, bajo el alero del paso de autonomía tradicional a autonomía relacional, y el interés nacional económico-comercial. En ese contexto, se evidencia que en más de dos décadas de política exterior, no se han logrado los objetivos discursivos respecto al crecimiento a cumplir, mucho menos en la actualidad, donde el crecimiento económico, en primer lugar, no alcanza el $2 \%$ anual, y donde el mismo crecimiento durante años no se ha visto reflejado en mayor igualdad y distribución de las riquezas.

El neoliberalismo se manifiesta en el contenido material y subjetivo de una vinculación exterior, que discursivamente pretende arraigarse en la integración de latinoamericana, pero que en la práctica reproduce los patrones de dominación de los centros sobre las periferias, es decir, de clases internacionales y trasnacionales de dominación política y económica, mediante una ideología orgánica (Cox, 1983). Por 
lo tanto, las acciones, discursos, ideas, identidades e instituciones que recrean la ideología orgánica o la estructura/fuerza social de la política exterior de Chile, se han manifestado, en las últimas tres décadas, en virtud de elites políticas cohesionadas para el mantenimiento del statu quo internacional, trasnacional y nacional.

Sea el apego por la tradición, el conservadurismo, la autopercepción de superioridad nacional, el valor por el territorio y la ley, como también el aislacionismo regional y su apertura comercial mono-productiva minera y marítima, aportan a un estilo pragmático o camaleónico, que se moldea al contexto hegemónico en virtud de los ya mencionados intereses ideológicos de dominación de elites transnacionales. Aquello demanda una emergencia de la reorientación del análisis, y la formulación de estrategias de inserción internacional por parte de los gobiernos de Chile.

\section{Referencias}

Adomeit, H. (1980). Ideología en la visión soviética de los asuntos internacionales. En Perspectivas del poder soviético en la década de 1980 (pp. 103-110). Londres: Palgrave Macmillan.

Álamos, P. (1999). Algunas fuentes históricas de la política exterior de Chile. Estudios internacionales, 32(126), 3-39.

Allan, P. (2001). Ontologías y explicaciones en la teoría de las Relaciones Internacionales. Revista Ciencia Política, 21(1), 77-106.

Alons, G. C. (2007). Predicting a state's foreign policy: state preferences between domestic and international constraints. Foreign Policy Analysis, 3(3), 211-232.

Aranda, G., y Riquelme, J. (2011). La política exterior de Chile desde 1990. Inserción internacional y prioridad regional. Cuaderno sobre relaciones internacionales, regionalismo y desarrollo, 6(11), 11-41.

Araya, E. (2017). Notas para una historia de las relaciones vecinales de Chile en el siglo XX. Revista chilena de relaciones internacionales, 1(1), 73-99.

Aron, R. (1963). Paz y Guerra entre las Naciones. Madrid: Revista de Occidente.

Berger, M., y Leiteritz, R. (2014). Antonio Gramsci: un pensador poco convencional en las Relaciones Internacionales. Bogotá: Universidad del Rosario.

Bernal-Meza, R. (2005). América Latina en el mundo el pensamiento latinoamericano y la teoría de las relaciones internacionales. Buenos Aires: Nuevohacer, GEL.

Bernal-Meza, R. (2016). Contemporary Latin American thinking on International Relations: theoretical, conceptual and methodological contributions. Revista Brasileira de Política Internacional, 59(1), 1-32.

Bizzozzero, L. (2007). La inserción internacional de Uruguay en la globalización: una mirada multidimensional frente al nuevo siglo. Seminario de inserción internacional del Uruguay. Cancillería de la República, Montevideo.

Briceño, J., Quintero, M., y Ruiz, D. (2013). El pensamiento estructuralista de la CEPAL sobre el desarrollo y la integración latinoamericana: reflexiones sobre su vigencia actual. Revista aportes para la integración latinoamericana, 19(28), 1-34.

Burchill, S. (2005). The national interest in international relations theory. Nueva York: Springer.

Colacrai, M., y Lorenzini, E. (2005). La Política exterior de Chile: ¿excepcionalidad o continuidad? Una lectura combinada de "fuerzas profundas" y tendencias. CONfines, 1, 45-63.

Correa, L., Salas, A., Soza-Amigo, S., y García-Pinzón, V. (2015). Entre el conflicto y el aislamiento: desarrollo, gobernabilidad y seguridad en las zonas fronterizas del norte y el sur de Chile a comienzos del siglo XXI. Idesia (Arica), 33(3), 73-77.

Correa, L., y García-Pinzón, V. (2012). Aunque las aguas nos dividan: las relaciones chileno-bolivianas y la construcción de una agenda común. Latinoamérica. Revista de Estudios Latinoamericanos, 54, 75-110.

Cox, R. (1981). Fuerzas sociales, Estados y Órdenes Mundiales: Más allá de la Teoría de Relaciones Internacionales. Journal of International Studies, 10, 126-155. 
Cox, R. (1983). Gramsci, hegemonía y relaciones internacionales: un ensayo sobre el método. Relaciones Internacionales, 31, 137-152.

Dahl, R., y San Martín, J. (1997). La poliarquía: participación y oposición. Editorial Tecnos.

Del Arenal, C., y Sanahuja, J. (2015). Teorías de las Relaciones Internacionales. Madrid: Editorial Tecnos.

Devetak, R. (2013). Critical Theory. En S. Burchill, y A. Linklater (eds.), Theories of international relations (137-160). Londres: Palgrave Macmillan.

Doyle, M. W. (1997). Ways of War and Peace: Realism. Liberalism, \& Socialism. Nueva York: WW Norton \& Company

Egerton, G. (1991). Ideology, Diplomacy, and International Organization: Wilsonism and the League of Nations in Anglo-American Relations, 1918-1920. En Anglo-American Relations in the 1920s. Londres: Palgrave Macmillan.

Fermandois, J. (2006). Inserción global y malestar regional: la política exterior chilena en el ciclo democrático, 1990-2006. Estudios Internacionales, 39(154), 91-99.

Flisfisch, A. (2011). La política exterior chilena y América del Sur. Revista Estudios Internacionales, 168, 115-141.

Foyle, D. (2003). Foreign policy analysis and globalization: public opinion, world opinion, and the individual. International Studies Review, 5(2), 155-202.

Fuentes, C. (2014). La política exterior de la transición chilena desde sus internas. Si somos americanos. Revista de Estudios Transfronterizos, 14(2), 133-157.

Gani, J. K. (2014). The Role of Ideology in Syrian-US Relations. Nueva York: Springer.

Gardini G. L., y Lambert P. (2011). Latin American Foreign Policies. Nueva York: Palgrave Macmillan.

Garretón, M. A. (2007). Matriz sociopolítica y desarrollo socio-económico en Chile. Recuperado de https://www.m anuelantoniogarreton.cl/documentos/artespanolmatrizippg.pdf

Gill, S., y Law, D. (1989). Global hegemony and the structural power of capital. International studies quarterly, 33(4), 475-499.

Gobetti, Z. (2009). Una revisión de la teoría de la paz democrática. Revista CS, 3, 39-74.

González, S., Barra, A., e Iturra, L. (2017). Imaginarios geográficos transfronterizos de Tarapacá: una revisión bibliográfica de estudios transfronterizos del norte tarapaqueño. Aldea Mundo, 44, 17-29.

González, S., y Correa, L. (2005). Cimentando la integración, pensamiento y cultura en el espacio subregional andino: El trabajo de Chile y Bolivia en la última década del siglo XX. Universidad Arturo Prat y Universidad Santiago de Chile. En H. Yesid Bernal (coord.), Siete cátedras para la integración. Bogotá: Convenio Andrés bello.

Gourevitch, P. (1996). La 'segunda imagen invertida': Orígenes internacionales de las políticas domésticas. Zona abierta, 74, 21-68.

Gramsci, A. (2005). Antología. Ciudad de México: Siglo XXI Editores.

Hudson, V. M. (2005). Foreign policy analysis: actor-specific theory and the ground of international relations. Foreign policy analysis, 1(1), 1-30.

Jenne, N., y Briones, S. (2018). Integración regional y la política exterior de Chile. ¿ Paradoja o acomodo? Estudios internacionales (Santiago), 50(189), 9-35.

Kaarbo, J. (2003). Foreign Policy Analysis in the Twenty-First Century: Back to Comparison, Forward to Identity and Ideas. International Studies Review, 5(2), 155-202.

Larraín, J. (2007). El concepto de ideología, Vol. 1: Carlos Marx. Santiago: Lom Editores.

Larraín, J. (2008). El concepto de ideología, Vol. 2: El marxismo posterior a Marx: Gramsci y Althusser. Santiago: Lom Editores.

Larraín, J. (2009). El concepto de ideología, Vol. 3: Irracionalismo, historicismo, positivismo: Nietzsche, Mannheim y Durkheim. Santiago: Lom Editores.

Larraín, J. (2010). El concepto de ideología, Vol. 4: Posestructuralismo, postmodernismo, postmarxismo. Santiago: Lom Editores. 
Lasagna, M. (1995). Las determinantes internas de la política exterior: un tema descuidado en la teoría de la política exterior. Revista Estudios Internacionales, 28(111), 387-409.

Lenin, V. I. I. (1961). Obras escogidas. Moscú: Editorial Progreso.

Linklater, A. (1990). Beyond realism and marxism: Critical theory and international relations. Londres: Springer.

Lukács, G., y Sacristán, M. (1975). Historia y consciencia de clase. Barcelona: Grijalbo.

Maira, L. (2011). América Latina en los años que vienen. En J. Ensignia, C. Fuentes, y M. Fernández (eds.), Política exterior en el Chile Post-Concertación: ¿quo vadis? (115-120). Santiago: Chile 21.

Martini, N. F. (2012). The role of ideology in foreign policy attitude formation. Iowa City: University of Iowa.

Martini, N. F. (2015). Foreign policy ideology and conflict preferences: A look at Afghanistan and Libya. Foreign Policy Analysis, 11(4), 417-434.

Marx, K. (2014). Antología. Buenos Aires: Siglo Veintiuno Editores.

Milner, H. (1997). Interests, institutions and information: Domestic politics and International relations. Princeton: Princeton University Press.

Möller, F., Iduya, S., y Thauby, S. (2007). Una estrategia nacional de largo plazo para Bolivia. En M. Artaza, y P. Milet (eds.), Nuestros vecinos (283-302). Santiago: Ril Editores.

Muñoz, H. (1982). Las relaciones exteriores del gobierno militar chileno. Revista Mexicana de Sociología, 44(2), 577-597.

Orias, R. (2015). La demanda marítima de Bolivia en La Haya: entre el pacta sunt servanda y la promisio est servanda. La balsa de piedra: revista de teoría y geoestrategia iberoamericana y mediterránea, 10, 5-14.

Oskanian, K. (2016). The Balance Strikes Back: Power, Perceptions, and Ideology in Georgian Foreign Policy, 19922014. Foreign Policy Analysis, 12(4), 628-652.

Ovando, C., y Aranda, G. (2013). La autonomía en la política exterior latinoamericana: evolución y debates actuales. Papel Político, 18(2), 719-742.

Ovando, C., y Ramos, R. (2016). Imaginarios geográficos en torno a la franja fronteriza de Tarapacá: el estado y los habitantes/migrantes. Scripta Nova. Revista Electrónica de Geografía y Ciencias Sociales, 20, 1-25.

Oyarzún, L. (2017). Chile en la Unasur: percepciones de actores clave sobre la organización. Revista Estudios Internacionales, 188, 9-36.

Parker J. (2011). Ideology, Race and Nonalignment in US Cold War Foreign Relations: or How the Cold War Racialized Neutralism Without Neutralizing Race. En Challenging US Foreign Policy (pp. 75-98). Londres: Palgrave Macmillan.

Portales, C. (2011). La reconstrucción de la identidad internacional de Chile. La política multilateral de la Concertación (1990-2010) y los nuevos desafíos para la política exterior. Washington, DC: Icso-UDP

Putnam, R. (1988). Diplomacy and domestic politics: The logic of the two level games. International Organization, 42(3), 427-460.

Ross, C. (2005). Chile en la doble asimetría: ensayo sobre política internacional. Revista Sí Somos Americanos, 7(1), 109-139.

Ross, C., y Leiva, S. (2016). La política de Chile hacia Bolivia, 1990-2009. Ni coordinación política, ni cooperación económica. Estudios Políticos, 50, 17-41.

Ruggie, J. (2009). Epistemología, ontología y el estudio de los regímenes internacionales. Revista Relaciones Internacionales (Geri), 12, 171-191.

Russell, R., y Tokatlian, J. (2003). De la autonomía antagónica a la autonomía relacional: una mirada teórica desde el Cono Sur Perfiles Latinoamericanos. Perfiles Latinoamericanos, 21, 159-194.

Ruz, M. (2011). Relación Chile-Argentina. En J. Ensignia, C. Fuentes, y M. Fernández (eds.), Política exterior en el Chile Post-Concertación: ¿quo vadis? (pp. 147-156). Santiago: Chile 21.

Salomón, M. (2001). La teoría de las relaciones internacionales en los albores del siglo XXI: diálogo, disidencia, aproximaciones. CIDOB d'afers internacionals, 56, 7-52. 
Sanahuja, J. A. (2012). Regionalismo post-liberal y multilateralismo en Sudamérica: El caso de Unasur. En A. Serbin (coord.), Anuario de Integración Regional de América Latina y el Caribe (pp. 19-72). Buenos Aires: Cries.

Shlaim, A. (2011). Batallas en el cinturón: ideología y luchas internas en la política exterior de Estados Unidos hacia el Medio Oriente 2001-2006 (disertación doctoral). Universidad de Oxford, Reino Unido.

Sunkel, O., y Zuleta, G. (1990). El neoliberalismo versus el neoestructuralismo en los años 90. Revista de la Cepal, 42, 35-53.

Telechea, J. M., y Zeolla, N. H. (2014). El pensamiento económico latinoamericano del desarrollo y la industrialización: estructuralistas y neoestructuralistas igiro o actualización? Rev. La Revista del CCC, 21, 1-13.

Tomassini, L. (1989). Teoría y Práctica de las Relaciones Internacionales. Santiago: Universidad Católica de Chile.

Van der Pijl, K. (1998). Trasnational classes and international relations. Ámsterdam: Centre for International Political Economy.

Van Klaveren, A. (1997). América Latina: hacia un regionalismo abierto. Estudios Internacionales, 30(117), 62-78.

Van Klaveren, A. (2011). La política exterior de Chile durante los gobiernos de la Concertación (1990-2010). Revista Estudios Internacionales, 169, 155-172.

Weldes, J. (2009). La Construcción de los Intereses Nacionales. En A. Santa Cruz (ed.), El constructivismo y las relaciones internacionales (pp. 367-417). Ciudad de México: CIDE.

Wilhelmy, M. (1979). Hacia un análisis de la Política Exterior chilena contemporánea. Estudios Internacionales, 48, 440-471.

Wilhelmy, M., y Lazo, R. (1997). La política multilateral de Chile en Asia-Pacífico. Estudios Internacionales, 30(117), 3-35.

Witker, I. (2000). Los conceptos interés nacional y regionalismo abierto en el acercamiento Chile/Mercosur. Política y Estrategia, 82, 124-137.

Witker, I. (2001). La cláusula democrática y la política exterior de Chile en los noventa: la singularidad instrumental a la elaboración teórica. Revista Universum, 16, 237-247.

\section{Notas}

[1] La denominada Alianza por Chile, hoy renombrada como Chile Vamos, la cual reúne a los partidos de derecha, y que han sido parte de los gobiernos de Sebastián Piñera en su primer periodo 2010-2014, y del actual, 2018-2021. La coalición política de centroizquierda que gobernó entre 1990 y 2010 mutó en un nuevo conglomerado denominado Nueva Mayoría para el segundo gobierno de Michelle Bachelet, 2014-2018.

[2] Cuando se señale la política exterior de Chile en este estudio, pareciera que se homologara a la política comercial, o a la diplomacia entre Estados, puesto que las prácticas e ideas de la política exterior chilena en este periodo se han desempeñado principalmente en estas facetas, subordinando otras áreas fundamentalmente a lo comercial, tal como se desarrolla a lo largo del texto, pero se entiende que conceptualmente son términos distintos.

[3] Además, la Teoría Crítica comprende la realidad objetiva como una construcción intersubjetiva, en donde las estructuras y las agencias son resultados de las fuerzas de la historia y la práctica de grupos humanos en interacción, donde se destaca "el papel activo de las mentes humanas en la constitución del mundo social, [el cual] no conduce a una negación de la realidad material, simplemente le da un diferente estado ontológico” (Devetak, 2013).

[4] Y la interpretación de Gramsci de Maquiavelo, el autor originario de la metáfora del Centauro.

[5] En este nuevo contexto, la autonomía de los estados (Bernal Meza, 2005), una vieja aspiración de las políticas exteriores latinoamericana, en tanto continente subalterno, ya no se busca por la vía de la contestación, autarquía o independencia de los centros, sino por la vía de ser protagonista de la nueva arquitectura regional de ideología liberal.

[6] Se refiere, fundamentalmente, a una democracia liberal procedimental, que le quita todo contenido social y económico de la aspiración de democracia, es decir, se promueve una idea de democracia que solo garantiza derechos civiles y políticos: libertad de expresión, y elecciones libres secretas y trasparentes (Ovando y Aranda, 2013), más no económicos y sociales, que son los valores que buscan garantizar las reformas políticas que se exigen hoy en Chile, como por ejemplo: garantías sociales en salud, educación, de pensiones, etc. En efecto, la mayoría de las sanciones a países de la región que infringen la cláusula se relacionan con infracciones a la libertad de expresión, como cierres de medios de comunicación y elecciones fraudulentas. 
* Artículo de investigación

Licencia Creative Commons CC BY 4.0

Cómo citar este artículo: González Pizarro, S. (2019). La política exterior de Chile y su ideología desde 1990. Papel Político, 24(1). https://doi.org/10.11144/Javeriana.papo24-1.peci 